\title{
Ophthalmologists should consider the causes of myopia and not simply treat its consequences
}

Myopia has been undergoing a major re-evaluation in recent years both by ophthalmologists and basic scientists, though for different reasons. For ophthalmologists the rise of refractive surgery in the past decade has seen myopia changing from a condition requiring optical correction to one that can be managed surgically with the aid of the excimer laser and other techniques. For basic scientists interested in the control of eye growth, the past decade has been equally revolutionary with a huge increase in the understanding of mechanisms by which eye growth is regulated by the quality of the retinal image. This research offers insights into why myopia develops in humans and offers clinicians a novel perspective from which to approach the management of myopia. Rather than attempting to alter corneal curvature to "treat" myopia, it may be possible to prevent or "cure" myopia by directly manipulating the growth mechanisms of the eye.

Epidemiological studies indicate that myopia represents a growing public health problem, particularly in the Far East. Singapore, for example, has seen an increase in the prevalence of myopia in young adults from $26 \%$ to $43 \%$ over a decade, reaching $65 \%$ in university graduates. ${ }^{1}$ This increase largely reflects the increasing levels of youth onset myopia and adult onset myopia. There is a wide variety of epidemiological evidence that suggests that environmental effects can influence the development of these forms of myopia. Within the Singaporean population, both the prevalence and degree of myopia correlate with the time spent in full time education. ${ }^{2}$ In populations with little genetic heterogeneity, such as Inuit populations, studies have revealed that within a generation, the incidence of myopia has risen dramatically in line with the onset of formal education and literacy. ${ }^{3}{ }^{4}$ In addition to this evidence for an environmental contribution to the aetiology of myopia, there is also abundant evidence for a genetic influence. These contrasting lines of evidence have stimulated the long running "nature versus nurture" debate, although it is now clear that myopia results from the interaction of environmental and genetic factors. ${ }^{5}$ However, the observed increases in myopia over a generation indicate that the modern myopic epidemic is being fuelled by environmental changes. Furthermore, environmental influences are more easily altered than our genetic make up. Understanding how the visual environment can influence eye growth should therefore be central to any attempts to alter the natural history of myopia.

The link between the visual environment and myopia lies in the quality of the retinal image. Experimental evidence in a range of species has revealed that in the absence of a clear retinal image, eye growth is disturbed resulting in deprivation myopia. ${ }^{6-8}$ Of much more relevance to human myopia are the recent findings that the primate eye can alter its growth depending on the direction and degree of defocus within the retinal image, modifying its growth to neutralise the effects of lenses placed in front of the eye during development. ${ }^{9}$ Such work demonstrates the role of the retinal image in the process that has become known as emmetropisation. This notion initially arose from the observation that the frequency of emmetropia in the population is far higher than expected from the observed variation in ocular variables influencing the refractive state such as corneal curvature and axial length. In most individuals these variables are balanced in order to achieve emmetropia, implying some form of optical regulation of eye growth. Myopia clearly represents a failure of the normal emmetropisation mechanisms. For late onset myopia, the association with educational attainment suggests that increased near work either disrupts normal emmetropisation mechanisms or results in regulation of ocular growth towards myopia as an adaptation to prolonged near work.

Unravelling how near work interacts with normal emmetropisation represents one potential avenue for blocking the environmental contribution in late onset myopia. The degree of defocus of the retinal image is dependent on the refraction of the eye, viewing distance, and the state of ocular accommodation. Although accommodation has been invoked as a cause of myopia for decades, early theories relied largely on unsubstantiated mechanical effects of ciliary muscle activity on the sclera rather than the impact on retinal image quality. If prolonged near work promotes the development of myopia as a result of retinal image quality, then the interaction between viewing distance and accommodation is likely to be of particular significance. Myopic children have been found to have poor accommodation for near targets ${ }^{10}$ resulting in hyperopic blur within the retinal image. Under such conditions myopia may represent a physiological adaptation to prolonged near work with the mechanisms of emmetropisation regulating eye growth to a state that minimises retinal image blur for near. This can only occur at the expense of producing myopia and retinal blur for distance. Such reasoning has led to a renewed interest in possible optical solutions, such as bifocal or varifocal lenses to prevent late onset myopia in high risk populations. Bifocal spectacles appear to reduce myopic progression, ${ }^{11}$ particularly when there is associated esophoria. If myopia is an adaptive physiological response to prolonged near work, correction of myopia with lenses during childhood may increase the final degree of myopia by requiring further adaptive changes in axial length to neutralise the effects of the lenses. Certainly in animal studies minus lenses do result in ocular growth towards myopia. Whether this implies that myopic children should be undercorrected remains controversial. Ultimately, resolving whether these findings are applicable in humans can only be achieved by appropriate clinical studies.

Another possible avenue that might allow manipulation or prevention of myopia has arisen from developments in our understanding of the pharmacological mechanisms by which retinal image quality influences eye growth. The possible impact of accommodation on myopia has been investigated in the past by using atropine to block accommodation. ${ }^{12}$ However, atropine also acts to block experimental myopia in species where the ciliary muscle is unaffected by atropine such as the chicken, ${ }^{13}$ implying that it is acting by a non-accommodative mechanism. It has been found that experimental myopia can be prevented by 
application of the selective muscarinic antagonist pirenzepine which acts on the $M_{1}$ receptor subtype. ${ }^{14}$ This subtype of muscarinic receptors is found within the retina rather than the ciliary muscle. In addition to muscarinic mechanisms, two other neurotransmitters have been implicated in the optical regulation of ocular growth - namely, dopamine $^{15}$ and VIP (vasoactive intestinal peptide). ${ }^{16}$ Dopamine and VIP are found within specific subpopulations of amacrine cells, suggesting a role for this poorly understood cell type in the regulation of eye growth. Amacrine cells represent a diverse population of neurons that are likely to perform a number of roles within the retina, but with their synaptic connections within the inner plexiform layer they are well placed to respond to retinal image quality.

Pharmacological manipulation of these growth mechanisms clearly offers a very direct means of altering the natural history of myopia. Selective muscarinic antagonists such as pirenzepine, a drug already in human use as a treatment for peptic ulcers, offer the prospect of influencing the signals that promote myopia without the confounding effects on the retinal image that result from the cycloplegia generated by atropine.

The one common thread in the various lines of research into the regulatory mechanisms of eye growth and experimental myopia is that this work has remained largely within the realms of the basic sciences. Indeed, a major criticism of this field is that much of the work has relied on animal models, such as the chicken, that are of questionable application to humans. Nevertheless, there is growing evidence that the primate eye displays similar regulatory growth mechanisms to the avian eye. Although a great deal of further research will be required to transfer this work to humans, there is a real prospect for dramatic alterations in the clinical management of myopia. In terms of both the optical and pharmacological manipulation of myopia, there are questions that can only be addressed by clinical studies. In light of recent developments such studies should be given high priority. However, such studies are only likely to take place if there is sufficient interest and enthusiasm from ophthalmologists. While it is certain that refractive surgery will play a major role in the ophthalmological management of myopia in the future, ophthalmologists should also recognise and take up the challenge of preventing or curing myopia by addressing its cause and not simply treating the consequences.

D I FLITCROFT

Institute of Ophthalmology, University College Dublin,

Dublin, Ireland

1 Tay MT, Au Eong KG, Ng CY, Lim-MK. Myopia and educational attainment in 421,116 young Singaporean males. Ann Acad Med Singapore 1992;21:785-91.

2 Au Eong KG, Tay TH, Lim MK. Education and myopia in 110,236 young Singaporean males. Singapore Med f 1993;34:489-92.

3 Morgan RW, Speakman JS, Grimshaw SE. Inuit myopia: an environmentally induced "epidemic"? Can Med Assoc f 1975;112:575-7.

4 Johnson GJ, Matthews A, Perkins ES. Survey of ophthalmic conditions in a Johnson GJ, Matthews A, Perkins ES. Survey of ophthalmic conditions in a
Labrador community. I Refractive errors. Br f Ophthalmol 1979;63:440-8. Labrador community. I Refractive errors. Br f Ophthalmol 1979;63:440-8.
Mutti DO, Zadnik K, Adams AJ. Myopia: the nature versus nurture debate Mutti DO, Zadnik K, Adams AJ. Myopia: the nature
goes on. Invest Ophthalmol Vis Sci 1996;37:952-7.

6 Wiesel TN, Raviola E. Myopia and eye enlargement after neonatal lid fusion Wiesel TN, Raviola E. Myopia and eye
in monkeys. Nature 1977;266:66-8.

7 in monkeys. Nature 1977;266:66-8. ciated with neonatal eyelid closure in human infants. Am $\mathcal{F}$ Ophthalmol 1981;91:197-200.

8 Wallman J, Turkel J, Trachtman J. Extreme myopia produced by modest changes in early visual experience. Science 1978;201:1249-51.

9 Hung LF, Crawford MLJ, Smith EL. Spectacle lenses alter eye growth and the refractive status of young monkeys. Nature Med 1995;1:761-5.

10 Gwiazda J, Thorn F, Bauer J, Held R. Myopic children show insufficient accommodative response to blur. Invest Ophthalmol Vis Sci 1993;34:690-4.

11 Goss DA, Grosvenor T. Rates of childhood myopia progression with bifocals as a function of nearpoint phoria: consistency of three studies. Optom Vis Sci 1990;67:637-40.

12 Bedrossian RH. The effect of atropine on myopia. Ophthalmology 1979;86:713-9.

13 Stone RA, Lin T, Laties AM. Muscarinic antagonistic effects on experimental chick myopia. Exp Eye Res 1991;52:755-8

14 Cottriall CL, McBrien NA. The $M_{1}$ muscarinic anatagonist pirenzepine reduces myopia and eye enlargement in the tree shrew. Invest Ophthalmol Vis Sci 1996;37:1368-79.

15 Schaeffel F, Bartmann M, Hagel G, Zrenner E. Studies on the role of the retinal dopamine/melatonin system in experimental refractive errors in chickens. Vision Res 1995;35:1247-64.

16 Stone RA, Laties AM, Raviola E, Wiesel TN. Increase in retinal vasoactive intestinal polypeptide after eyelid fusion in primates. Proc Natl Acad Sci USA 1988;85:257-60. 